\title{
Non Cognitive Neuropsychiatric Impairments in Alzheimer's Disease
}

\section{AV Medvedeva* and NN Yahno}

Neurological Department of First Moscow Medical University, Moscow, Russian Federation

\begin{abstract}
Alzheimer's disease (AD) is one of the most frequent neurodegenerative disorders. AD is usually associated with non-cognitive neuropsychiatric impairment (NCNI) as apathy, depression, anxiety, emotional labiality, sleep disorders.

Methods: 131 patients with $A D$ (mild, moderate degree) were included in the investigation according to the diagnostic criteria of DSM IV and MKB 10. 45 AD patients were on galantamine, 43-memantin and 43-combined therapy. The control group includes 45 patients. In our investigation in the main group of $A D$ patients the duration of the disease was from 6 months to 4.3 years, on average 3.3 years. Standard neuropsychological an investigation was performed in $A D$ and control group which included the following tests- MMSE: Mini Mental State Examination, FAB: Frontal Assessment Battery), clock drawing test, 12 world list immediate and delayed recall (subscore, total). Neuropsychiatric investigation includes neuropsychyatric inventory (NPI-Cummings)
\end{abstract}

Results: Correlation analysis between cognitive and non-cognitive neuropsychiatric impairments in combined group showed Total NPI-MMSE, $r=-0.312, p=0.032$; Total NPI-FAB, $r=-0.41, p=0.03$, Total NPI-FAB, $r=-0.41 p=0.03$, Apathy-12 world delayed recall (total), $r=-0.45 p=0.001$, Apathy-12 world learning test delayed recall with help $r=-0.45$ $p=0.001$, Sleep scale-12 word learning test immediate recall $(r=+0.44 p=0.03$, Sleep disorders- 12 worlds learning test-delayed recall $r=+0.55 p=0.001$ ). Correlation between NPI and EEG data showed Total NPI-spectral power in T3, $r=+0.46 p=0.048$, Depression-spectral power of delta in C $r=+0.34 p=0.032$, Depression-spectral power of theta band in $\mathrm{C} 4 \mathrm{r}=+0.32 \mathrm{p}=0.032$, Apathy-spectral power in theta band in $\mathrm{C} 3, r=+0.37 p=0.01$, Apathy-spectral power in theta band in $\mathrm{C} 4 \mathrm{r}=+0.33 p=0.031$, Emotional liability-spectral power in delta $\mathrm{F} 1 \mathrm{r}=+0.47 p=0.027$, Emotional liability-spectral power in F2 $r=+0.46 p=0.049$, Total NPI-intra hemispheric coherence of theta in T3-T4 $r=-0.45 p=0.048$, DepressionIntra hemispheric coherence in $\mathrm{C} 3-\mathrm{C} 4 \mathrm{r}=-0.35 \mathrm{p}=0.033$, Apathy-Intra hemispheric coherence in C3-C4 $r=-0.45 p=0.048$, Apathy-Intra hemispheric coherence of theta in T3-T4 $r=-0.32 p=0.03$, Emotional liability-Intra hemispheric coherence in F1-F2 $r=-0.46 p=0.026$, Emotional liability-Intra hemispheric coherence in T3-T4 $r=-0.47 p=0.048$.

Conclusion: There were found significant correlations between cognitive and non-cognitive neuropsychiatric impairments. So the data gives significant possibility to think that NCNI are the obligatory sign of AD.

Keywords: Alzheimer's disease; Non-cognitive neuropsychiatric impairment; Apathy; Neuropsychyatric inventory

\section{Introduction}

The study question is to find whether non cognitive neuropsychiatric impairment (NCNI) are isolated from neurodegenerative disorder, associated with the main neurodegenerative process or appear as a reaction on $\mathrm{AD}$.

The problem of non-cognitive neuropsychiatric impairment in patients with dementia is widely discussed, but there is a lack of information focused of the connection of non-cognitive neuropsychiatric impairment and neurodegeneration.

The other problem is the application of neuroleptics for treating behavioral and emotional disorders which have side effects on cognitive functions. The connection of NCNI with neurodegeneration will give future approaches for therapy of these symptoms; will definitely reduce the number of drugs.

Alzheimer's disease $(\mathrm{AD})$ is one of the most frequent neurodegenerative disorders. More than $50 \%$ of population suffers of cognitive decline of Alzheimer's type. At the age 60-64 years the dementia of Alzheimer type is about $1 \%$ of population, after 85 the prevalence is $40 \%$ [1-11].

Dementia is result of long term progression of mild cognitive impairment (MCI) [7,12-18].

The study question is to find whether non-cognitive neuropsychiatric impairment are isolated from neurodegenerative disorder, associated with the main neurodegenerative process or appear as a reaction on $\mathrm{AD}$.
$\mathrm{AD}$ is usually associated with non-cognitive neuropsychiatric impairment (NCNI) [4-6,19-26]. In the whole population AD is seen in $53 \%$, in clinical population $-88 \%$.

Apathy, depression, anxiety, emotional liabilities are more frequent in early stages of AD. With the progression of dementia NCNI become more evident and psychotic symptoms (aggression, hallucinations and others) appeared. Psychotic symptoms are the predictor of more rapid progression of the disease.

The NCNI correlate with the degree of functional disability and cognitive decline, especially in frontal executive functions. NCNI are the main reason of distress of patients and their relatives and could be the main reason of hospitalization to specialized memory centres because they are usually connected with severe cognitive declinedementia.

Apathy, depression, anxiety, sleep disorders are in prevalence at the early stage of $\mathrm{AD}$. With the longer duration of the disease appeared

*Corresponding author: AV Medvedeva, Neurological Department of First Moscow Medical University, Moscow, Russian Federation, Tel: +79165084008 ; E-mail: anastasia_medved@mail.ru

Received December 26, 2016; Accepted December 29, 2016; Published December 31, 2016

Citation: Medvedeva AV, Yahno NN (2016) Non Cognitive Neuropsychiatric Impairments in Alzheimer's Disease. Int J Neurorehabilitation 3: 241. doi: 10.4172/2376-0281.1000241

Copyright: ( 2016 Medvedeva AV, et al. This is an open-access article distributed under the terms of the Creative Commons Attribution License, which permits unrestricted use, distribution, and reproduction in any medium, provided the original author and source are credited. 
psychotic symptoms (hallucinations, etc.) [27-43]. Aggression and psychotic symptoms are the predictor of more rapid progression of the disease.

The variety of $\mathrm{NCNI}$ in $\mathrm{AD}$ is changing individually during the disease which is connected with the worsening and remission [38]. Moran showed that NCNI are very variable in the beginning of the disease in the population of light degree of dementia [35].

There are 3 big groups of NCNI which are present in AD:

1. Low prevalence of NCNI

2. High rate of depression and anxiety

3. High prevalence of aggression [35]

Teng et al. [38] analysed the evolution of NCNI in AD. In the light degree (MMSE 21 and more) NCNI were observed in $80-90 \%$. Depression (50\%), apathy (51\%), emotional liability (38\%) was more frequent. Less frequent were aggression (34\%) and anxiety (30\%). There was seen the increase of all NCNI on the stage of moderate cognitive impairments and in dementia (MMSE 11-20). In prevalence were apathy $(80 \%)$, anxiety $(65 \%)$ and aggression $(55 \%)$. Hallucinations were observed in $10-15 \%$ of patients. On the degree of severe cognitive impairments (MMSE less than 11) apathy was in 92\%, aggression- $85 \%$ and anomaly movement disorders- $84 \%$. Aggression, depression, apathy and anomaly movement activity on the degree of severe dementia were observed more frequently [29].

NCNI are predominately connected with the main pathologic process in AD. Anxiety and depression could be also as a reaction on cognitive decline and daily activity disorder. For the treatment of NCNI usually are used neuroleptics and symptomatic "antidementia" drugs. There are data of the positive influence of inhibitors of NMDA receptors (akatinol memantin) on NCNI. Inhibitors of acetylcholinesterase (galantamin) also reduce the degree of NCNI and prolong its appearance on the long term treatment.

In treatment of NCNI the combination of "antidementia" drugs with antidepressants is used. These combinations help to treat depression and anxiety [19]. Inhibitors of acetylcholinesterase, akatinol memantin, psychostimulators and DOPA-agonists are effective in treatment of apathy.

Cummings showed that NPI scale is effectively used for the evaluation of NCNI, which gives information about the frequency and degree of each syndrome and the level of distress of patient and relatives [42].

NPI scale seems to be the most informative, which gives the possibility to evaluate the whole spectrum of NCNI, evaluate the clinical evidence of each symptom and the degree of distress.

Neurovisualisation (PET) helps to evaluate the connection between some of the NCNI symptoms with glucose hypo metabolism and hypoperfusion in specific brain regions and the impact of some neuromediator processors in pathogenesis of the symptoms. The combination of fMRI and EEG gives more diagnostic possibilities for diagnosis the early stage of cognitive decline [29,33]. In all NCNI symptoms there are specific neurometobolic disorders of neuromediators. Aggression is described by cholinergic deficit. Apathy is characterized by the disorder of cholinergic and dopaminergic pathways.

Depression is characterized by insufficiency of cholinergic, dopaminergic, serotoninergic and noradrenalinergic brain systems, which is approved by pathological disorders in nucleus Meinert, substantia nigra, nucleus raphus, locus caeruleus. The possibility of regression of NCNI on the symptomatic "antidementia" drugs gives the possibility to think that pathogenesis of NCNI in $\mathrm{AD}$ is connected with the main pathologic process.

There is no common opinion on the most frequent NCNI, their influence on concrete cognitive function and therapy on different stages of $\mathrm{AD}$. The diagnostic value of investigating NCNI in AD is not good evaluated. It is really important to evaluate and treat NCNI, because they negatively influence on daily activity of the patient.

\section{Patients and Methods}

All investigated patients were due to diagnostic criteria of $\mathrm{AD}$ MKB 10 [31] and DSM-IV [2].

We have investigated patients with $\mathrm{AD}$ of mild and moderate stage.

131 patients with $\mathrm{AD}$ (mild, moderate degree) were included in the investigation. The degree of dementia was evaluated by clinical dementia rating scale (Clinical Dementia Rating Scale-Sum of Boxes (CDR-SB). $45 \mathrm{AD}$ patients were on galantamine, 43-memantin and 43-combined therapy.

The control group includes 45 patients which were similar by age and gender characteristics with the other groups. In our investigation in the main group of $\mathrm{AD}$ patients the duration of the disease was from 6 months to 4.3 years, on average 3.3 years. In control group of AD patients the cognitive disorders lasted from 2.5-6.7 years, on average 4.5 years.

The duration of cognitive disorders was from the moment of diagnosis and beginning of symptomatic "antidementia" therapy with akatinol memantine, galantamine or their combination. Light degree of dementia was in the $68 \%$ of patients, moderate in $32 \%$. The same situation with the degree of cognitive disorders was in the group of $\mathrm{AD}$ patients on long term treatment in prevalence were patients with light degree of dementia.

So, the main group of $\mathrm{AD}$ and the group on long term treatment had same characteristics (age, gender, part of patients with light and severe degree of dementia). The group of $\mathrm{AD}$ patients on long term treatment differed from the $\mathrm{AD}$ main group with longer duration of treatment and longer duration of the disease.

$\mathrm{AD}$ patients more frequently have complain on memory loss (85.5\%), brain activity (78.8\%), and difficulties in finding the proper word (17.9\%). There were complaints on social and daily disadaptation. In neurological status in $70 \%$ were found sighs of pseudo bulbar syndrome- reflexes of oral automatism, asymmetry of reflexes, dysbasia $37.5 \%$ and postural instability- $27.1 \%$.

The main group did not significantly differed from the group on long term treatment. The patients with $\mathrm{AD}$ did not have arterial hypertension with unstable duration, hyperlipidaemia; there were no major atherosclerosis in arteries by ultrasound investigation, no diabetes mellitus.

Standard neuropsychological investigation was performed in $\mathrm{AD}$ and control group which included the following tests- MMSE-Mini Mental State Examination [14], FAB-Frontal Assessment Battery) [7], clock drawing test [36], 12 world list immediate and delayed recall (subscore, total) [37].

Neuropsychiatric investigation includes-neuropsychyatric inventory (NPI) [31]. NPI consists of several subscales (total score, depression, apathy, emotional liability, anxiety, aggression, anomal 
movement activity, hallucinations, delirium, sleep disorders, appetite, euphoria,). There was also used alone apathy scale.

Electrophysiological investigation was performed in resting state and with specific cognitive tasks. There was used 10-20 system with investigation of spectral power and intra/interhemispheric coherence. CT, MRI scans were performed in $98 \%$. There was found atrophy of parieto-temporal regions. None of the patients had vascular lesions, so vascular dementia or combined dementias were excluded. Hachinsky scale was more than 4 (2-6) in all groups of patients - there is no value for vascular dementia. Patients with $\mathrm{AD}$ had no significant vascular risk factors, no vascular lesions on MRI. Vascular or combined type of dementia was excluded.

A statistical analysis was performed by SPSS v. 17.0. It was used Student criteria (t-test), Mann-Whitney (U-test) for comparement of groups, Spearmen coefficient, Anova analyses for dynamic comparement. A two samples t-test was used to compare groups $\mathrm{AD}$ and healthy elderly subjects. The Mann-Whitney test was also used as a confirmatory test of significance given the nonparametric nature of the data.

\section{Results}

The data of cognitive and non-cognitive impairments are presented in Tables 1-3. There was significant difference between the groups on therapy and controls in MMSE, FAB, Clock drawing test. There was found significant difference in cognitive and non-cognitive functions between the group of $\mathrm{AD}$ on memantin and galantamin and controls.

We did not find difference between the AD groups on acatinol memantin and galantamin in 12 world learning test (immediate recall, immediate recall with help, delayed recall, delayed recall with help). There was found difference only between AD groups and controls in 12 world learning test.

The most frequent symptoms from NPI scale were-depression, apathy, anxiety. The similar results were found in $\mathrm{AD}$ patients by other investigators [15].

\begin{tabular}{|c|c|c|c|c|}
\hline \multirow[b]{2}{*}{ Group Test } & \multicolumn{2}{|c|}{ Main group } & \multirow{2}{*}{$\begin{array}{l}\text { Combined therapy } \\
\qquad(n=43)\end{array}$} & \multirow[b]{2}{*}{$\begin{array}{c}\text { Control group } \\
(n=45)\end{array}$} \\
\hline & $\begin{array}{l}\text { Monotherapy } \\
\text { Galantamin } \\
(n=45)\end{array}$ & $\begin{array}{c}\text { Monotherapy } \\
\text { Acatinol Memantin } \\
(n=43)\end{array}$ & & \\
\hline MMSE & $20 \pm 2.1^{*}$ & $22 \pm 1.2^{*}+$ & $22.3 \pm 1.5^{\star} \#$ & $29 \pm 1.4$ \\
\hline Clock drawing test & $6.8 \pm 2.1^{*}$ & $7 \pm 1.2^{*}+$ & $7 \pm 1.2^{*} \#$ & $9,6 \pm 1.1$ \\
\hline FAB & $13 \pm 1.4^{*}$ & $14 \pm 1.5^{*}+$ & $14.2 \pm 1.6^{\star} \#$ & $17 \pm 1$ \\
\hline
\end{tabular}

Notes: There are only significant data presented in the table

*- significant data between groups and controls,

+- significant data between the group of AD on memantin and galantamin

\#- significant data between the group of $A D$ on galantamin and combined

Table 1: Results of the data of cognitive functions in $A D$ patients on different types of therapy and their combination.

\begin{tabular}{|c|c|c|c|c|}
\hline \multirow[b]{2}{*}{ Group Test } & \multicolumn{2}{|c|}{ Main group } & \multirow[b]{2}{*}{$\begin{array}{c}\text { Combined } \\
\text { samples t-test was used to } \\
\text { compare }\end{array}$} & \multirow[b]{2}{*}{$\begin{array}{c}\text { Control } \\
(n=45)\end{array}$} \\
\hline & $\begin{array}{l}\text { Monotherapy } \\
\text { galantamin } \\
(n=45)\end{array}$ & $\begin{array}{l}\text { Monotherapy memantin } \\
\qquad(n=43)\end{array}$ & & \\
\hline 12 word learning test total & $7,3 \pm 1.2^{*}$ & $7,7 \pm 1.3^{*}$ & $7.3 \pm 1.4^{*}$ & $11,7 \pm 1.1$ \\
\hline 12 word list immediate recall & $6.3 \pm 1.2^{*}$ & $6.7 \pm 1.3^{*}$ & $6.3 \pm 1.4^{*}$ & $8.6 \pm 1.1$ \\
\hline 12 word list immediate recall with help & $1 \pm 1.1^{*}$ & $1 \pm 1.1^{*}$ & $1 \pm 1.1^{*}$ & $3.1 \pm 1.1$ \\
\hline 12 word list delayed recall total & $6,2^{*} \pm 1$ & $6,1 \pm 1.1^{*}$ & $6.8 \pm 1.3^{*}$ & $11,3 \pm 1.1$ \\
\hline 12 word list delayed recall & $5.2 \pm 1.1^{*}$ & $5.1 \pm 1.1^{*}$ & $5.8 \pm 1.1^{*}$ & $7.9 \pm 1.1$ \\
\hline 12 word list delayed recall with help & $1 \pm 1.1^{*}$ & $1 \pm 1.1^{*}$ & $1 \pm 1.1^{*}$ & $3.4 \pm 1.1$ \\
\hline
\end{tabular}

Note: *There are only significant data presented in the table between the groups and controls

Table 2: Results of the data of 12 word learning tests in $A D$ patients on different types of therapy and their combination.

\begin{tabular}{|c|c|c|c|c|}
\hline \multirow{2}{*}{ Group symptom } & \multicolumn{2}{|c|}{ AD patients } & \multirow{2}{*}{$\begin{array}{l}\text { AD patients-combined } \\
\qquad(n=43)\end{array}$} & \multirow{2}{*}{$\begin{array}{c}\text { Control group } \\
(n=45)\end{array}$} \\
\hline & Galantamin $(n=45)$ & Memantin (n=43) & & \\
\hline NPI - total & $13.34 \pm 2.1^{*}$ & $13.78 \pm 1.2^{*}$ & $13,22 \pm 1.2^{*}$ & $8.18 \pm 1.1$ \\
\hline Depression & $3.1 \pm 1.2^{*}$ & $2.91 \pm 1.1$ & $2.85 \pm 1.3$ & $1.85 \pm 1$ \\
\hline Apathy & $2.0 \pm 1.2^{*}$ & $2.3 \pm 1.1^{*}$ & $1.7 \pm 1.1$ & $1.35 \pm 1.1$ \\
\hline Emotional liability & $2.5 \pm 1.2^{*}$ & $2.3 \pm 1.2^{*}$ & $1.9 \pm 1.1$ & $1.35 \pm 1.1$ \\
\hline Anxiety & $1.86 \pm 1.1^{*}$ & $1.7 \pm 1.1^{*}$ & $1.08 \pm 1^{*}$ & $0.58 \pm 0.5$ \\
\hline Agression & $1.0 \pm 1.1^{*}$ & $0.69 \pm 1.1$ & $1.04 \pm 1.1^{*}$ & $0.55 \pm 0.5$ \\
\hline Anomal movement activity & $0.7 \pm 1.1^{*}$ & $0.6 \pm 0.4$ & $0.73 \pm 0.4$ & $0.54 \pm 0.5$ \\
\hline Sleep disorders & $0.7 \pm 0.4$ * & $0.52 \pm 0.5$ & $0.7 \pm 0.4$ & $0.53 \pm 0.3$ \\
\hline Euphoria & $0.8 \pm 0.5^{*}$ & $0.69 \pm 0.3$ & $1 \pm 0.4^{*}$ & $0.52 \pm 0.4$ \\
\hline Loss of inhibition & $0.58 \pm 0.4$ & $0.54 \pm 0.5$ & $0.55 \pm 0.4$ & $0.51 \pm 0.4$ \\
\hline Appetite disorder & $0.57 \pm 0.34$ & $0.53 \pm 0.4$ & $0.52 \pm 0.4$ & $0.5 \pm 0.4$ \\
\hline Delirium & $0.5 \pm 0.3^{*}$ & $0.5 \pm 0.5^{*}$ & $0.5 \pm 0.5^{*}$ & 0 \\
\hline Hallucinations & $0.5 \pm 0.5^{*}$ & $0.5 \pm 0.5^{*}$ & $0.5 \pm 0.5^{*}$ & 0 \\
\hline
\end{tabular}

Notes: *There are only significant data presented in the table between groups of patients and controls

Table 3: Results of NPI in group on memantin, galantamin, combined therapy group of AD patients and control group. 


\begin{tabular}{|c|c|c|c|c|}
\hline Group Correlations & $\begin{array}{l}\text { Common group of } \\
\text { patients }(n=131)\end{array}$ & $\begin{array}{l}\text { Patients on galantamine } \\
\qquad(n=45)\end{array}$ & $\begin{array}{l}\text { Patients on memantine } \\
\qquad(n=43)\end{array}$ & $\begin{array}{l}\text { Patients on combined } \\
\text { treatment }(n=43)\end{array}$ \\
\hline Total NPI-MMSE & $\begin{array}{l}r=-0.312 \\
p=0.032\end{array}$ & & & \\
\hline Total NPI-FAB & $\begin{array}{l}r=-0.41 \\
p=0.03\end{array}$ & & $\begin{array}{l}r=-0.47 \\
P=0.036\end{array}$ & \\
\hline Apathy-12 world delayed recall (total) & $\begin{array}{l}r=-0.45 \\
p=0.001\end{array}$ & $\begin{array}{l}r=-0.69 \\
p=0.005\end{array}$ & $\begin{array}{l}r=-0.46 \\
p=0.049\end{array}$ & $\begin{array}{l}r=-0.69 \\
p=0.004\end{array}$ \\
\hline Apathy-12 world learning test delayed recall with help & $\begin{array}{l}r=-0.43 \\
p=0.001\end{array}$ & $\begin{array}{l}r=-0.65 \\
p=0.005\end{array}$ & $\begin{array}{l}r=-0.43 \\
p=0.049\end{array}$ & $\begin{array}{l}r=-0.64 \\
p=0.003\end{array}$ \\
\hline Sleep scale- 12 word learning test immediate recall & $\begin{array}{r}r=+0.44 \\
p=0.03\end{array}$ & $\begin{array}{l}r=+0.56 \\
p=0.036\end{array}$ & & \\
\hline Sleep disorders- 12 worlds learning test-delayed recall & $\begin{array}{l}r=+0.55 \\
p=0.001\end{array}$ & & $\begin{array}{l}r=+0.61 \\
p=0.007\end{array}$ & $\begin{array}{l}R=+0.55 \\
P=0.026\end{array}$ \\
\hline Aggression-TrailA & $\begin{array}{c}r=-0.367 \\
p=0.01\end{array}$ & & $\begin{array}{l}r=-0.46 \\
p=0.05\end{array}$ & \\
\hline Emotional lability-12 world learning test immediate recall & $\begin{array}{l}r=-0.38 \\
p=0.001\end{array}$ & $\begin{array}{l}r=-0.65 \\
p=0.008\end{array}$ & & \\
\hline \multicolumn{5}{|l|}{ Emotional liability-clock drawing test } \\
\hline Anxiety- clock drawing test & & & & \\
\hline
\end{tabular}

Notes: There are only significant data presented in the table. NPI: Neuropsychiatric Inventory (total score, depression, apathy, emotional liability, anxiety, aggression, anomal movement activity, hallucinations, delirium, sleep disorders, appetite, euphoria); MMSE: Mini Mental State Examination; FAB: Frontal Battery Assessment

Table 4: Results of correlation analysis of cognitive and non-cognitive disorders in AD patients on different types of therapy and their combination.

The data of correlation analysis between cognitive and noncognitive neuropsychiatric impairments was performed. There were found negative correlations between degree of emotional liability, and clock drawing test (Table 4$),(\mathrm{r}=-0.47, \mathrm{p}=0.026)$, between anxiety and clock drawing test $(\mathrm{r}=-0.42, \mathrm{p}=0.049)$.

In the whole combined $\mathrm{AD}$ group on treatment (monotherapy of memantine, excelon (galantamin), combined therapy) there were found significant negative correlations between NPI (total) and MMSE and FAB tests, apathy with world learning test recall delayed test, emotional liability with world learning test immediate recall.

Besides, there were found positive correlations between the quality of sleep disorders and results of world learning test (immediate and delayed recall). In small groups of AD patients which were divided by type of monotherapy there were found less correlations in comparison with the combined group of patients (probably because of the less number of patients).

\section{Correlation between EEG Coherence and Spectral Power with the Results of Non-cognitive Neuropsychiatric Impairments}

There was found positive correlation between total NPI, apathy scale, depression, emotional liability and data of spectral power of EEG in theta, delta bands in frontal, central and temporal regions (Table 5).

Severe psychotic symptoms (hallucinations) were connected with the increased spectral power in theta and delta bands. Negative correlations were found between total NPI, apathy, depression, emotional liability and data of intra hemispheric coherence in theta and delta bands (Table 5). Severe psychopathic disorders by NPI scale were connected with low intra hemispheric coherence. Probably, functional disconnection between left and right hemispheres plays the major role in presence of hallucinations and other psychiatric disorders.

It is important to mention that major correlations between EEGchanges and psychiatric disorders include the most valuable symptomsdepression, apathy, emotional liability.

\begin{tabular}{|l|c|}
\hline Group Correlations & $\begin{array}{c}\text { Common group before } \\
\text { treatment }(\mathbf{n}=\mathbf{1 3 1})\end{array}$ \\
\hline Total NPI-spectral power in T3 & $\begin{array}{r}\mathrm{r}=+0.46 \\
\mathrm{p}=0.048\end{array}$ \\
\hline Depression-spectral power of delta in C3 & $\begin{array}{l}\mathrm{r}=+0.34 \\
\mathrm{p}=0.032\end{array}$ \\
\hline Depression-spectral power of theta band in C4 & $\begin{array}{l}\mathrm{r}=+0.32 \\
\mathrm{p}=0.032\end{array}$ \\
\hline Apathy-spectral power in theta band in C3 & $\mathrm{r}=+0.37$ \\
& $\mathrm{p}=0.01$ \\
\hline Apathy-spectral power in theta band in C4 & $\mathrm{r}=+0.33$ \\
& $\mathrm{p}=0.031$ \\
\hline Emotional liability-spectral power in delta F1 & $\mathrm{r}=+0.47$ \\
$\mathrm{p}=0.027$ \\
\hline Emotional liability-spectral power in F2 & $\mathrm{r}=+0.46$ \\
\hline Total NPI-intra hemispheric coherence of theta in T3-T4 & $\mathrm{p}=0.049$ \\
\hline Depression-Intra hemispheric coherence in C3-C4 & $\mathrm{r}=-0.45$ \\
$\mathrm{p}=0.048$
\end{tabular}

Notes: r: Correlation; p: Statistical Significance

NPI: Neuropsychiatric Inventory (total score, depression, apathy, emotional liability, anxiety, aggression, anomal movement activity, hallucinations, delirium, sleep disorders, appetite, euphoria); MMSE: Mini Mental State Examination; FAB: Frontal Battery Assessment

Table 5: Correlations between spectral power and coherence of EEG and NP data.

\section{Discussion}

It was found that all significant pathophysiological correlations were between theta and delta bands. Probably it could be explained by the fact that on the stage of light and moderate $\mathrm{AD}$ exactly these 
bands are the major markers of the pathophysiological disorders of EEG.

Cognitive disorders, depression, apathy, emotional liability and EEG- changes in theta and delta bands are signs of the common pathophysiological complex which characterizes $\mathrm{AD}$ on the stage of light and moderate dementia. We have found the high level of NCNI in all investigated patients, the degree of clinical signs was significantly higher than in control group.

In the structure of NCNI were predominately depression, apathy, emotional liability and anxiety. The same symptoms were also found in clinical form. The evaluation of clinical NCNI is included in the possibility of NPI [39].

All authors underscore the importance of evaluation of NCNI of all degree, because they could significantly increase to the degree of clinically significant by the progression of the disease. NCNI in AD have periods of remission and exacerbation. It is important to mention that in all patients NCNI were polysymptomatic. It could be diagnosed because of the 4 and more symptoms in every patient.

The presence of depression, anxiety, emotional liability and apathy was found in other investigations.

Lyketsos et al. after statistical analysis of NPI data divided 3 specific blocks of NPI of emotional and behaviour disorders. First $59 \%$ of patients had minimum of psychopathic symptoms. Second with the major impact of depression, anxiety, emotional liability that was called "affective block" in $27 \%$.Third with more psychotic symptoms hallucinations "psychotic block" in $13 \%[28,29]$. The authors underlined that apathy is one of the most common symptom in $\mathrm{AD}$; it was observed in $80 \%$ and is present in each block.

In our investigation there were patients predominately of affective block plus apathy. The polysymptomacity could be one of the sigh of organic disorder. Psychotic symptoms in our group were found in $4.5 \%$, in clinical form ( $4>$ points by NPI) there was no psychotic symptoms.

By the data of presence of non-psychotic symptoms our investigation is similar to the international data $[10,11,28,29]$. In data of psychotic symptoms there were different results. Teng et al. [39] showed that on the stage of moderate AD (MMSE $11-20$ points) the major part of patients is with hallucinations (10-15\%).

Not very big number of psychotic symptoms could be explained in our investigation by the fact that between ambulatory patients were predominately patients on the early stage of AD- $69 \%$ with light degree of dementia, 31\% moderate, MMSE levels were 23-13.

It could be also explained by the fact that patients with psychopathic symptoms usually visit psychiatry hospitals. The correlation analysis which was performed in our investigation showed significant correlations between NCNI and low points in cognitive tests - on memory, attention, visual-spatial orientation, frontal regulatory functions, MMSE.

We explained it by the fact of negative influence if NCNI on cognitive functions. The correlations, which were found, give the possibility to suggest that cognitive and NCNI are the signs of one complex which is specific for $\mathrm{AD}$.

We have found significant negative correlation between apathy and 12 word delayed recall test in the group of $\mathrm{AD}$ on and without treatment. High and significant correlation between amnestic functions and apathy could be explained by the fact that apathy is the dominant symptom in NCNI disorders and 12 delayed recall test -in cognitive disorders. But it could be also explained by the other fact.

Apathy is one of the most common syndromes at all stages of $\mathrm{AD}$ and it is connected with the main pathologic process [29]. In apathy the most important role is the dysfunction of dopaminergic, glutamatergic and cholinergic systems of the brain.

Cummings et al. suppose that apathy is mostly connected with cholinergic deficit, which could explain its high presence in $\mathrm{AD}$ and connection with cholinergic deficit. That could explain its high frequency and connection with memory insufficiency [33,39]. The absence of major differences by character of NCNI in patients with different courses of treatment give the possibility to think that therapeutic efficacy of the investigated drugs in treatment of NCNI appear on the early stages of treatment and by long term treatment stop the progression of major process.

There was found significant efficacy of galantamine in our investigation. The severity of aggression, hallucinations, affective disorders, anxiety decreases on short term treatment (4 months). The therapeutic efficacy of memantin also appeared very early on the therapy of several months $[8,9]$.

\section{Conclusion}

NCNI in patients with $\mathrm{AD}$ are widely presented. Our investigation found significant increase of cognitive functions, decrease of NCNI by symptomatic "antidementia" treatment with memantin, galantamin and their combination.

The debut of NCNI in old age, together with the cognitive disorders, it's positive dynamic on symptomatic "antidementia" drugs, significant correlations between cognitive and NCNI make possible to think that genesis of NCNI by AD is predominately connected with the main pathologic process. It could be lightly connected with psychological reaction on cognitive decline.

By specific therapy exactly NCNI are significantly regressed, while cognitive functions become significantly better but did not reach the lighter stage. So the data gives significant possibility to think that NCNI are the obligatory sign of $\mathrm{AD}$.

\section{Summary}

Alzheimer's disease (AD) is one of the most frequent neurodegenerative disorders. More than $50 \%$ of population suffers of cognitive decline of Alzheimer's type. The aim was to investigate NCNI in mild and moderate patients with $\mathrm{AD} .131$ patients with $\mathrm{AD}$ were investigated. There were several groups-group of monotherapy with memantin, monotherapy with galantamin, combined therapy with memantin and galantamin, control group.

We have used the following scales-MMSE, FAB, 12 word learning test (immediate and delayed recall), NPI. We have found that the most frequent symptoms were- depression, apathy, anxiety- "affective block". Our data are similar with the results of other authors. Our investigation found significant increase of cognitive functions, decrease of NCNI by symptomatic "antidementia" treatment with memantin, galantamin and their combination.

The debut of NCNI in old age, together with the cognitive disorders, it's positive dynamic on symptomatic "antidementia" drugs, significant correlations between cognitive and NCNI make possible to think that genesis of NCNI by $\mathrm{AD}$ is predominately connected with the main 
pathologic process. It could be lightly connected with psychological reaction on cognitive decline.

By specific therapy exactly NCNI are significantly regressed, while cognitive functions become significantly better but did not reach the lighter stage. So the data gives significant possibility to think that NCNI are the obligatory sign of AD.

\section{References}

1. Di Carlo A, Baldereschi M, Amaducci L, Lepore V, Bracco L, et al. (2002) Incidence of dementia, Alzheimer's disease and vascular dementia in Italy. The ILSA Study. J Am Geriatr Soc 50: 41-48.

2. Fitz AG, Teri L (1994) Depression, cognition and functional ability in patients with Alzheimer's disease. J Am Geriatr Soc 42: 186-191.

3. Jorm AF (1985) Subtypes of Alzheimer's dementia: A conceptual analysis and critical review. Psychol Med 15: 543-553.

4. Landes AM, Sperry SD, Strauss ME (2005) Prevalence of apathy, dysphoria and depression in relation to dementia severity in Alzheimer's disease. J Neuropsychiatry Clin Neurosci 17: 342-349.

5. Moran M, Walsh C, Lynch A, Coen RF, Coakley D, et al. (2004) Syndromes of behavioural and psychological symptoms in mild Alzheimer's disease. Int $J$ Geriatr Psychiatry 19: 359-364.

6. Morris JH (1997) Alzheimer's disease. Cambridge University Press, Cambridge, UK.

7. Sarazin M, Horn N, Dubois B (2007) Natural decline and prognostic factors in clinical diagnosis and management of Alzheimer disease. Informa UK Limited, UK

8. Vosnesenskay TG (2010) Non-cognitive neuropsychiatric disorders by cognitive impairment in elderly patients. J Neurol 2: 4-11.

9. Yahno NN, Zaharov VV, Lokshina AB (2005) Light cognitive impairment by encephalopathy. Journal of Neurology and Psychiatry of Korsakov 2: 13-17.

10. Zaharov VV, Yahno NN (2003) Memory disorders. Geotar Med 110-111.

11. Zaharov VV (2004) Cognitive disorders. By reduction of Yahno NN.

12. Almkvist O, Basun H, Bäckman L, Herlitz A, Lannfelt L, et al. (1998) Mild cognitive impairment-an early stage of Alzheimer's disease? J Neural Transm Suppl 54: 21-29.

13. David AS, Fleminger S, Kopelman MD, Lovestone S, Mellers J (2009) Lishman's organic psychiatry: A Textbook of Neuropsychiatry. Willey-Blackwell, USA.

14. Guimarães HC, Levy R, Teixeira AL, Beato RG, Caramelli P (2008) Neurobiology of apathy in Alzheimer's disease. Arq Neuropsiquiatr 66: 436-443.

15. Lyketsos CG, Steinberg M, Tschanz JT, Norton MC, Steffens DC, et al. (2000) Mental and behavioral disturbances in dementia: Findings from the Cache County Study on Memory in Aging. Am J Psychiatry 157: 708-714.

16. Mortimer JA, Ebbitt B, Jun SP, Finch MD (1992) Predictors of cognitive and functional progression in patients with probable Alzheimer's disease. Neurology 42: $1689-1696$

17. Orr WB (2004) Apathy in the older adult. Why you should care. Geriatrics 59 34-36.

18. Petersen RS, Touchon J (2005) Consensus on mild cognitive impairment. Res Pract Alzheimers Dis 10: 24-32.

19. Bózzola FG, Gorelick PB, Freels S (1992) Personality changes in Alzheimer's disease. Arch Neurol 49: 297-300.

20. Damulin IV (2002) Alzheimer disease and vascular dementia. Reduction Yahno NN 2002: 86
21. De Carli C (2003) Mild cognitive impairment: prevalence, prognosis, aetiology and treatment. Lancet Neurol 2: 15-21.

22. Forst $H$, Burns A, Levy R, Cairns N, Luthert $P$, et al. (1993) Neuropathological correlates in behavioral disturbances in confirmed Alzheimer disease. $\mathrm{Br} J$ Psychiatry 163: 364-368.

23. Frisoni GB, Padovani A, Wahlund LO (2004) The predementia diagnosis of Alzheimer disease. Alzheimer Dis Assoc Disord 18: 51-53.

24. Guimarães HC, Levy R, Teixeira AL, Beato RG, Caramelli P (2008) Neurobiology of apathy in Alzheimer's disease. Arq Neuropsiquiatr 66: 436-443.

25. Levin OS (2008) The relationship of depression and dementia in elderly patients. The treatment of nervous diseases 3: 3-9.

26. Luis CA, Barker WW, Loewenstein DA, Crum TA, Rogaeva E, et al. (2004) Conversion to dementia among two groups with cognitive impairment. A preliminary report. Dement Geriatr Cogn Disord 18: 307-313.

27. Lyketsos CG, Lopez O, Jones B, Fitzpatrick AL, Breitner J, et al. (2002) Prevalence of neuropsychiatric symptoms in dementia and $\mathrm{MCl}$ : results from the cardiovascular health study. JAMA 288: 1475-1483.

28. Medvedeva A, Keeser D, Meindl T, Teipel SJ, Karch S, et al. (2008) Functiona connectivity in patients with early Alzheimer's disease, $\mathrm{MCl}$ and healthy controls as assessed by fMRI and EEG. Klin Neurophysiol 40: 58.

29. Vataja R (2006) Prevalence and significance of behavioral symptoms. The Fourth Kuopia Alzheimer symposium. Kuopia, Finland.

30. Apostolova LG, Cummings JL (2008) Neuropsychiatric manifestation in $\mathrm{MCl}$ systematic review of the literature. Dement Geriatr Cogn Disord 25: 115-126.

31. Beck AT, Ward CH, Henderson $\mathrm{H}$ (1961) An inventory for measuring depression. Arch Gen Psychiatry 4: 561-571.

32. Bózzola FG, Gorelick PB, Freels S (1992) Personality changes in Alzheimer's disease. Arch Neurol 49: 297-300.

33. Coen RF, Swanwick GRJ, O'Boyle CA, Coacley D (1997) Behaviour disturbance and other predictors of career burden in $A D$. Int $\mathrm{J}$ Geriatr Psychiatry 12: 331 336.

34. Damulin IV (2002) Alzheimer disease and vascular dementia. Reduction Yahno NN 2002: 86.

35. Lezak MD (1995) Neuropsychological assessment. Oxford University Press, New York.

36. Grober E, Buschke H, Crystal H, Bang S, Dresner R (1988) Screening for dementia by memory testing. Neurology 38: 900-903.

37. Teng E, Cummings JL (2007) Clinical diagnosis and management of AD Informa UK Limited, UK.

38. Ternovoi IV, Damulin IV (1991) Quantitative evaluation of computer tomographic characteristics of the brain by neurodegenerative diseases. Med Radiology 7 : 21-26.

39. Jones MK, Menzies RG (2000) Danger expectancies, self-efficacy and insight in spider phobia. Behav Res Ther 38: 585-600.

40. Koponen HJ (2006) Assessment of Behavioral symptoms. Abstracts The Fourth Kuopia Alzheimer symposium 2006 Kuopia Finland, 2-4.

41. Mayeux R, Honig LS, Tang MX, Manly J, Stern Y, et al. (2003) Plasma A[beta]40 and $A[$ beta]42 and Alzheimer's disease: Relation to age, mortality and risk. Neurology 61: 1185-1190.

42. McCarty HJ, Roth DL, Goode KT, Owen JE, Harrell L, et al. (2000) Longitudina course of behavioral problems during Alzheimer's disease: Linear versus curvilinear patterns of decline. J Gerontol A Biol Sci Med Sci 55: M200-M206.

43. WHO (1995) International classification of diseases and health problems WHO, Geneva. 